\title{
EFEKTIFITAS MODEL ADAPTASI ROY DALAM MANAGEMEN KASUS DEMAM NEUTROPENIA PADA ANAK DI RUMAH SAKIT CIPTO MANGUNKUSUMO
}

\author{
Rosa Melati $^{1}$, Allenidekania $^{2}$, Happy Hayati $^{2}$ \\ 1. Mahasiswa Spesialis Keperawatan Anak dan Pengajar Akademi Keperawatan Manggala Husada Jakarta, \\ Jalan Jatinegara Barat No. 15, Kampung Melayu, Jakarta Timur \\ 2. Staf Pengajar Keilmuwan Keperawatan Anak Fakultas Ilmu Keperawatan Universitas Indonesia, Depok, \\ Jawa Barat \\ E-mail: ocha_melati@yahoo.co.id
}

\begin{abstract}
Abstrak
Demam neutropenia merupakan komplikasi yang terjadi paska kemoterapi. Tujuan Karya Ilmiah Akhir adalah menggambarkan aplikasi model adaptasi Roy dalam merawat anak dengan kanker yang mengalami masalah demam neutropenia dan pencapaian kompetensi praktik spesialis keperawatan anak. Peran perawat yang dilakukan selama praktik adalah pemberi asuhan, advokator, konselor, pendidik, kolaborator, peneliti dan inovator berlandaskan etik dan legal dalam keperawatan. Pendekatan model adaptasi Roy diaplikasikan pada 5 kasus dan proses keperawatan yang dilalui adalah pengkajian perilaku, pengkajian stimulus, diagnosa keperawatan, tujuan keperawatan, intervensi dan evaluasi. Evaluasi yang didapat adalah nilai ANC lebih dari 1000 mm3 saat anak keluar dari ruang rawat demam neutropenia, dan gejala klinis mengalami perbaikan. Model adaptasi Roy dapat diterapkan pada anak kanker di ruang rawat anak dalam upaya mencapai proses adaptasi dan meningkatkan kualitas hidup anak.
\end{abstract}

Kata Kunci: kanker, demam neutropenia, model adaptasi Roy

\begin{abstract}
Neutropenic febrile is a complication effect of post chemotherapy treatment. This final paper aimed to describe the application of Roy's Adaptation Model in caring for children with cancer experiencing neutropenic febrile and to describe the achievement of pediatric nurse specialist student's competencies in clinical practice. During the residency programme, role as caregiver, advocate, educator, collaborator, researcher, and innovator was conducted based on ethic and legal in nursing issues. Roy's Adaptation Model was implemented on 5 pediatric clients. Nursing process was conducated by behavior and stimuli assessment, nursing diagnosis, nursing outcome, intervention, and evaluation. The children with neutropenia febrile experienced ANC value more than $1000 \mathrm{~m} 3$ after the care. Roy's Adaptation Model can be applied in caring for children with cancer in order to improve children's quality of life.
\end{abstract}

Keywords: Cancer, Febrile Neutropenia, Roy Adaptation Model

\section{Pendahuluan}

Kemoterapi merupakan pengobatan dengan menggunakan zat kimia. Salah satu efek samping yang dapat terjadi akibat kemoterapi adalah demam neutropenia (Sposito, et al, 2015). Demam neutropenia merupakan salah satu kondisi toksisitas akibat kemoterapi yang memiliki efek samping mielosupresi.

Demam neutropenia adalah suatu kondisi dimana jumlah sel darah putih mengalami penurunan sehingga kemampuan tubuh untuk melindungi diri dari infeksi menjadi berkurang (Joyce, 2006). Risiko 
neutropenia semakin besar jika jumlah absolute neutrophile count kurang dari 500/ mm3 atau kurang dari 1000/ mm3 (Laksmaiah et. al., 2014). Demam neutropenia ditandai dengan demam lebih dari $38,3^{0} \mathrm{C}$ atau jika dalam satu jam dilakukan 2 kali pengukuran suhu dengan hasil 38, $0^{\circ} \mathrm{C}$ (Oberoi, Suthar, Bansa \& Marwah, 2013).

Sebagian demam neutropenia dapat disembuhkan dengan cepat, namun $10 \%$ kasus demam neutropenia menyebabkan infeksi serius dan kematian (Ahn et, al, 2010). Intervensi yang diberikan oleh perawat dalam menangani kasus demam neutropenia adalah mencegah komplikasi neutropenia, memantau kondisi neutropenia dan memberikan pendidikan kesehatan tentang perawatan pasien neutropenia sehingga dapat menyelamatkan hidup pasien.

Demam neutropenia pada anak dengan kanker menyebabkan perubahan pada anak dan keluarga. Perubahan tersebut terjadi berhubungan dengan faktor fisik, sosial, ekonomi dan kelelahan emosional. Anak yang didiagnosa kanker memerlukan waktu pengobatan dan hari perawatan yang panjang serta berulang kali. Selain itu penuh dengan ketidakpastian terhadap kesembuhan penyakit.

Hal ini memerlukan strategi koping yang baik untuk anak dan keluarga agar keluarga dan anak dapat melalui semuanya dengan menyenangkan dan dapat beradaptasi dengan kondisi yang ada (Sposito, Rodrigues, Sparapani, Pfeifer, Lima, \& Nascimento, 2015). Proses adaptasi tersebut dapat diberikan melalui pendekatan pada anak dan keluarga menggunakan Model Adaptasi Roy.

Tujuan dari asuhan keperawatan pada pasien demam neutropenia adalah melindungi pasien dari komplikasi yang memberatkan akibat infeksi nosokomial, sehingga terjadi peningkatan kualitas hidup pasien.

\section{Metode Penelitian}

Penelitian kuantitatif dengan menggunakan desain kuasi eksperimental. Penelitian kuasi ini menggunakan pre test dan post test without control. pengambilan sampel dengan menggunakan teknik consecutive sampling yaitu pemilihan sampling berdasarkan semua objek yang datang dan sesuai dengan kriteria penelitian yang dilakukan di rumah sakit Cipto Mangunkusumo. Jumlah besar sampel yang digunakan pada penelitian ini adalah 8 anak. Tidak ada sampel yang dropout dalam penelitian.

Alat pengumpulan data yang digunakan adalah (1) algoritma demam neutropenia untuk melakukan pengkajian awal, pemeriksaan awal pasien dan stratifikasi kelompok demam neutropenia; (2) format 
pengkajian model adaptasi Roy untuk

melakukan pengkajian perilaku dan

stimulus, menentukan diagnosa

keperawatan, tujuan keperawatan,

intervensi dan evaluasi keperawatan. (3) kuisioner pre test dan post test; (4) lembar

observasi kepatuhan cuci tangan dan

lembar observasi penggunaan masker serta

jumlah pengunjung pasien.

\section{Hasil Rekapitulasi Data Saat Pengkajian Awal Dan Evaluasi Akhir}

\begin{tabular}{|c|c|}
\hline Pengkajian awal & Evaluasi akhir \\
\hline Responden yang ada berjumlah 8 orang & $\begin{array}{l}\text { Jumlah responden menjadi } 7 \text { orang. Satu orang } \\
\text { meninggal, pada hari terakhir evaluasi. }\end{array}$ \\
\hline $\begin{array}{l}\text { Dari } 8 \text { responden yang ada usia terbanyak } \\
\text { adalah usia remaja, jenis kelamin perempuan } \\
\text { dengan diagnosa medis ALL dan AML. }\end{array}$ & $\begin{array}{l}\text { Dari } 8 \text { responden yang ada usia terbanyak adalah usia } \\
\text { remaja, jenis kelamin perempuan dengan diagnosa } \\
\text { medis ALL dan AML. }\end{array}$ \\
\hline $\begin{array}{l}\text { Keluhan saat masuk adalah demam lebih dari } \\
38^{0} \mathrm{C} \text { dan nilai } \mathrm{ANC}<500 \mathrm{~mm} 3 \text {. }\end{array}$ & $\begin{array}{l}\text { Saat keluar ruang demam neutropenia } 7 \text { responden } \\
\text { sudah bebas demam } 2-3 \text { hari. Saat keluar rumah sakit } 6 \\
\text { responden memiliki nilai ANC }>1000 \mathrm{~mm} 3 \text { dan } 1 \\
\text { responden memiliki nilai ANC } 118 \mathrm{~mm} 3 \text {. }\end{array}$ \\
\hline $\begin{array}{l}\text { Penyakit penyerta saat masuk ruang demam } \\
\text { neutropenia: }\end{array}$ & $\begin{array}{l}\text { Penyakit penyerta saat keluar ruang demam } \\
\text { neutropenia: }\end{array}$ \\
\hline 1. Batuk 8 orang & Batuk 3 orang \\
\hline 2. Diare 2 orang & Diare 1 orang \\
\hline 3. Stomatitis 6 orang & Stomatitis 5 orang \\
\hline $\begin{array}{l}\text { Diagnosa keperawatan yang ditegakkan pada } \\
\text { pengkajian awal }\end{array}$ & $\begin{array}{l}\text { Diagnosa keperawatan yang teratasi pada evaluasi } \\
\text { akhir: }\end{array}$ \\
\hline 1. Hipertermi: 8 & Hipertemia: 0 \\
\hline 2. bersihan jalan napas tidak efektif: 8 & bersihan jalan napas tidak efektif: 3 \\
\hline 3. Diare: 2 & Diare: 1 \\
\hline 4. Gangguan Mukosa anal: 1 & Gangguan Mukosa anal: 1 \\
\hline 5. Kerusakan mukosa oral: 6 & Kerusakan mukosa oral: 5 \\
\hline 6. Risiko Perdarahan: 7 & Risiko Perdarahan: 1 \\
\hline $\begin{array}{l}\text { 7. Ketidak seimbangan nutrisi kurang dari } \\
\text { kebutuhan tubuh: } 8\end{array}$ & $\begin{array}{l}\text { Ketidak seimbangan nutrisi kurang dari kebutuhan } \\
\text { tubuh: } 8\end{array}$ \\
\hline $\begin{array}{l}\text { Klasifikasi kelompok risiko saat masuk ruang } \\
\text { demam neutropenia adalah kelompok risiko } \\
\text { tinggi }\end{array}$ & $\begin{array}{l}\text { Klasifikasi kelompok risiko saat keluar ruang demam } \\
\text { neutropenia adalah kelompok risiko rendah } 6 \text { responden } \\
\text { dan } 2 \text { masih kelompok risiko tinggi }\end{array}$ \\
\hline $\begin{array}{l}\text { Kepatuhan menggunakan masker (lembar } \\
\text { observasi): } 8 \text { pasien menggunakan masker saat } \\
\text { melakukan pemeriksaan di luar ruang } \\
\text { perawatan. } 8 \text { pasien tidak menggunakan } \\
\text { masker pada kondisi lainnya. }\end{array}$ & $\begin{array}{l}\text { Kepatuhan menggunakan masker (lembar observasi): } 8 \\
\text { pasien menggunakan masker saat melakukan } \\
\text { pemeriksaan di luar ruang perawatan, sementara pada } \\
\text { kondisi lain masker tidak digunakan }\end{array}$ \\
\hline $\begin{array}{l}\text { Kepatuhan cuci tangan (menggunakan lembar } \\
\text { observasi) } 8 \text { responden melakukan cuci tangan } \\
\text { selama } 10-15 \text { detik dan } 8 \text { responden melakukan } \\
\text { cuci tangan setelah dari kamar mandi. Namun } \\
\text { yang lainnya lebih banyak tidak dilakukan. }\end{array}$ & $\begin{array}{l}\text { Kepatuhan cuci tangan (menggunakan lembar } \\
\text { observasi) semua responden melakukan cuci tangan } \\
\text { selama 10-15 detik dan setelah dari kamar mandi. } 8 \\
\text { responden mencuci tangan setelah terkena cairan tubuh } \\
\text { pasien. Namun yang lainnya masih sama, lebih banyak } \\
\text { tidak dilakukan. }\end{array}$ \\
\hline $\begin{array}{l}\text { Penunggu dan pengunjung pasien lebih dari } \\
\text { satu }\end{array}$ & Penunggu dan pengunjung pasien lebih dari satu \\
\hline $\begin{array}{l}\text { Hasil pre test Pertanyaan yang diberikan } \\
\text { kepada keluarga pasien tentang mengapa } \\
\text { anaknya dirawat di ruang demam neutropenia, } \\
\text { dijawab oleh: } 2 \text { keluarga dengan jawaban tidak }\end{array}$ & $\begin{array}{l}\text { Hasil post test } 8 \text { keluarga mengatakan bahwa anaknya } \\
\text { dirawat karena hasil ANC menurun sehingga daya } \\
\text { tahan tubuhnya menurun. } 7 \text { keluarga pasien mengetahui } \\
\text { neutropenia adalah penurunan hasil laboratorium }\end{array}$ \\
\hline
\end{tabular}




\begin{abstract}
tahu atau tidak mengerti.
10 keluarga menjawab bahwa anaknya mengalami penurunan imunitas tubuh. Dari 10 keluarga 7 diantaranya mengerti bahwa demam neutropenia menyebabkan anaknya mudah terinfeksi sehingga harus dirawat di ruangan yang khusus dan 3 keluarga tidak tahu efek

leukosit dan trombosit serta $\mathrm{Hb}$ yang diakibatkan oleh efek samping kemoterapi dengan gejala demam lebih dari $38^{\circ} \mathrm{C}$. Cara perawatan anak dengan demam neutropenia 8 responden mengatakan dengan melakukan mengukur suhu tubuh anak, cuci tangan, menjaga kebersihan lingkungan, mandi, sikat gigi, dan menggunakan masker.
\end{abstract} dari demam neutropenia. Semua keluarga mengatakan tidak tahu cara merawat anak dengan demam neutropenia.

Berdasarkan hasil observasi terhadap tindakan cuci tangan yang dilakukan keluarga pasien hanya 2 keluarga yang benar tetapi kadang mereka lupa cuci tangan dan keluarga lainnya kurang tepat dalam cuci tangan.

satu ibu pasien mengatakan bahwa tamu yang berkunjung kadang batuk dan ibu pasien tidak enak untuk menegur menggunakan masker. Ibu pasien tersebut juga tidak memakaikan masker pada anaknya karena anaknya menolak.

\section{Pembahasan}

Pengkajian menurut Roy dibagi dalam 2 tahap yaitu pengkajian perilaku dan pengkajian stimulus. Pengkajian perilaku terdiri dari pengkajian fisiologis, konsep diri, fungsi peran dan interdependen. Pengkajian stimulus yaitu pengkajian fokal, kontekstual dan residual. Diagnosa medis pasien adalah AML, ALL, LMNH, Rhabdomiosarkoma, Retinoblastoma dan Neuroblastoma. Usia responden bervariasi dari todller sampai remaja. Demam neutropenia dapat terjadi pada pasien dengan berbagai usia dan diagnosa medis terutama bila kanker sudah mencapai ke sumsum tulang. Dari seluruh responden yang masuk ruang demam neutropenia terdapat keluhan suhu lebih dari $38,3^{0}$ Celcius, nilai absolute neutrophile count kurang dari $500 \mathrm{~mm}^{3}$, dan batuk.
Namun berdasarkan hasil observasi kepatuhan cuci tangan dari 8 responden masih sering lupa cuci tangan, serta 8 responden menolak pemakaian masker, dan menggunakan masker setelah diingatkan.
Menurut Laksmaiah (2014); Oberoi, Suthar, Bansa dan Marwah (2013) pasien demam neutropenia masuk ruang perawatan karena suhu lebih dari $38,3^{0}$ Celcius, nilai absolute neutrophile count kurang dari $500 \mathrm{~mm}^{3}$. Kondisi ini menyebabkan daya imunitas pasien menurun sehingga mudah terinfeksi. Salah satu tanda inflamasi adalah peningkatan suhu tubuh dan infeksi penyerta dapat terjadi disemua sistem tubuh. Infeksi yang dapat terjadi pada sistem pernapasan salah satunya adalah batuk. Begitu pala infeksi yang dapat terjadi pada sistem pencernaan adalah mukositis/ stomatitis dan diare.

Diagnosa utama yang terjadi pada pasien dengan demam neutropenia adalah hipertemia, kerusakan mukosa oral, ketidakseimbangan nutrisi kurang dari kebutuhan tubuh, dan risiko perdarahan. Diagnosa ini diangkat karena pasien 
demam neutropenia memiliki gejala awal demam lebih dari $38,3^{0}$ Celcius, selain demam efek dari kemoterapi lainnya adalah mukositis sehingga diangkat diagnosa keperawatan kerusakan mukosa oral, dengan adanya stomatitis maka nafsu makan menurun sehingga diangkat masalah ketidakseimbangan nutrisi. Risiko perdarahan terjadi karena pada demam neutropenia dapat terjadi penurunan semua komponen darah termasuk trombosit sehingga diangkat diagnosa risiko perdarahan. Diagnosa keperawatan lainnya dapat ditegakkan tergantung dari infeksi penyakit penyerta.

Seluruh responden masuk pada kelompok risiko tinggi. Hal ini terjadi karena saat masuk demam pasien lebih dari $39^{0}$ Celsius dan absolute neutrophile count kurang dari $500 \mathrm{~mm}^{3}$ serta terdapat penyakit penyerta antara lain batuk, diare dan mukositis.

Dari 8 responden menggunakan masker jika melakukan pemeriksaan diluar ruangan rawat. Sementara pada kondisi lainnya pasien tidak mau menggunakan masker karena merasa pengap. Hal ini terjadi karena pasien dan keluarga kurang memahami sepenuhnya perlindungan pasien terhadap infeksi melalui penularan udara/ droplet. Kepatuhan cuci tangan (menggunakan lembar observasi) semua responden melakukan cuci tangan selama 10-15 detik dan setelah dari kamar mandi.
8 responden mencuci tangan setelah terkena cairan tubuh pasien . Namun pada kondisi lainnya cuci tangan tidak dilakukan dengan alasan lupa. Selain itu pengunjung pasien masih lebih dari satu. Solusi pada permasalahan ini adalah pasien dirawat diruang isolasi dan perawat harus memperhatikan perilaku pasien dan keluarga pasien secara ketat, sehingga pasien lebih terlindungi dan risiko penularan infeksi dapat diminimalkan. Selain itu perawat harus selalu mengingatkan pasien untuk membatasi jumlah pengunjung, selalu menggunakan masker dan mencuci tangan sebelum dan sesudah melakukan tindakan.

Pembahasan intervensi pada kasus ini lebih banyak membahas tentang implementasi pencegahan infeksi atau meluasnya infeksi pada pasien dengan demam neutropenia sehingga intervensi yang dilakukan adalah Mengelompokkan klasifikasi risiko, memantau tanda-tanda vital (ttv) tiap 2 jam, melakukan kompres dengan air hangat, memberi obat antipiretik jika demam lebih dari $38^{\circ} \mathrm{C}$. menjaga kestabilan klinis pasien dengan memantau tingkat kesadaran, memantau tanda-tanda vital, melakukan observasi tanda dan gejala klinis pasien serta laporan pasien secara verbal.

Mencegah tingkat keparahan infeksi dilakukan dengan cuci tangan sesering 
mungkin, menganjurkan pengunjung menggunakan masker atau menganjurkan pasien menggunakan masker. Menganjurkan pasien menggunakan masker jika ruangan sedang dibersihkan (dipel/ disapu), mengganti gorden/ skreen secara rutin, menjaga kenyamanan dan kebersihan lingkungan pasien, meningkatkan nutrisi pasien dengan memberikan makan porsi kecil tiap 2 jam, mengajarkan pencegahan infeksi pada keluarga, memberikan posisi kepala lebih tinggi, memonitor perdarahan, mencegah untuk sikat gigi dan menganti dengan berkumur, melakukan auskultasi suara nafas tambahan, kolaborasi pemberian obat batuk. menganjurkan teknik relaksasi nafas dalam.

\section{Kesimpulan}

Model konsep Roy meliputi pengkajian pengkajian perilaku dan pengkajian stimulus, diagnosa keperawatan, tujuan keperawatan, intervensi, dan evaluasi. Pengkajian dilakukan dengan menggali perilaku melalui fungsi fisiologis, fungsi peran, fungsi konsep diri dan interdependen. Sementara pengkajian stimulus dengan mengkaji status fokal, kontekstual dan residual. Pengkajian spesifik pada demam neutropenia adalah peningkatan suhu tubuh, leukopenia, trombositopenia, $\mathrm{Hb}$ menurun dan nafsu makan menurun serta adanya fokus infeksi yang menyertai.

Diagnosa keperawatan spesifik yang dapat ditegakkan pada demam neutropenia adalah Hipertermia, ketidakefektifan jalan napas, kerusakan mukosa oral, gangguan rasa nyaman nyeri, ketidakseimbangan nutrisi kurang dari kebutuhan tubuh dan risiko perdarahan, tujuan keperawatan serta intervensi dilakukan dengan menggunakan prinsip Roy dan menggabungkan dengan nursing intervention clacification/ NIC dan Nursing outcome/ NOC.

Evaluasi menunjukkan hasil yang bervariasi. Satu pasien pulang walau ANC masih $118 \mathrm{~mm} 3$ untuk menghindari infeksi nosokomial, satu pasien dengan ANC 1202 mm3 dipindahkan ke ruang 110 untuk perbaikan kondisi pasien dan rencana kemoterapi berikutnya, sementara pasien lainnya pulang karena nilai ANC sudah lebih dari $1000 \mathrm{~mm} 3$ dan penyakit penyerta teratasi. Namun satu orang meninggal pada hari terakhir evaluasi karena kondisi memburuk.

\section{Ucapan Terima Kasih}

Peneliti mengucapkan terimakasih kepada responden yang telah berpartisipasi dalam penelitian ini. 


\section{Referensi}

Ahn S., et al. (2011). Predictive factors of poor prognosis in cancer patients with chemotherapy-induced febrile neutropenia. Support Care Cancer 19:1151-1158. DOI 10.1007/s00520-010-0928-4

Alligood, M.R, \& Tomey, A.M. (2010). Nursing theorists and their works. 6th ed. St. Louis: Mosby Elsevier, Inc

American Cancer Society. (2015). What are the most common types of childhood cancers?. 3 April 2015. http://www.cancer.org/cancerinch ildren American Childhood Organization. (2015).

Childhood cancer statistic. 5 Agustus 2015.http://www.acco.org/childho od-cancer-institute

Bryant A. L., \& Albrecht A. (2014). Management of Febrile Neutropenia in A Patient With Acute Leukemia. J Emergency Nursing 40:377-81. doi.org/10.1016/j.jen.2013.07.021

Canterbury District Health Board. Management of Oncology Patients with Neutropenia. No date. http://interwebd/cytotoxic/Policies/ Oncology Neutropenia Policy.doc

Donohue R. B. (2006). Development and Implementation of a Risk Assessment Tool for Chemotherapy-Induced Neutropenia. Oncology Nursing Forum 10.1188/06.ONF.347-352
Farley A et al (2012) Blood components. Nursing Standard. vol 27 no 13. 27, 13, 35-42.

Fawcett J. (2005). Middle Range nursing Theories are necessary for the Advancement of the Discipline. Aquichan, 5(001), 32 - 43

Friese C. R., (2006). Chemotherapy induced Neutropenia: Important New Data to Guide Nursing Assessment and Management. Cancer therapy and supportive care.

Gibson F., et al. (2013). Developing a national 'low risk' febrile neutropenia framework for use in children and young people's cancer care. Support Care Cancer, 21:1241-1251Doi 10.1007/s00520-012-1653-y

Gibson, T. M., \& Robison L. L. (2015). Impact of cancer therapy related exposures on late mortality in childhood cancer survivors. American Chemical Society Journal.

dx.doi.org/10.1021/tx500374k

Chem. Res. Toxicol. 28, 31-37

Hockenberry, M. \& Wilson, D. (2009). Essential of pediatric nursing. St Louis:Mosby year book.

Joyce A. (2006). Care of patients with neutropenia. Clinical Journal of Oncology Nursing 10.1188/06.164-166

Julia B. G. (1995). Nursing Theories, The Base for Profesional Nursing Practice. $4^{\text {th }}$ edition. Appleton \& lange Norwalk, Connecticut. 
Lakshmaiah K. C., Abhayakumar S. M., Shetty R., Loknath D., Jayashree R. S., \& Govindbabu K. (2014). Management of febrile neutropenia in solid organ malignancies following chemotherapy. Journal of Cancer Research and Therapeutics. Volume 10. DOI: 10.4103/09731482.137908

Langhorne, E, M., Fulton, S, J., \& Otto, E,

S. (2007). Oncology nursing. $5^{\text {nd }}$ ed.St Louis: Mosby Elsevier.

Lindqvist H., Carlsson G., Moell J., Winiarski J., \& Sundin M. (2015). Neutropenia in childhood: a 5 year experience at a tertiary center. Eur J Pediatr 174:801807. Doi 10.1007/s00431-0142465-5

Miller, E., Jacob, E., \& Hockenberry, M.J. (2011). Nausea, pain, fatigue, and multiple symptomps in hospitalized children with cancer. Oncology Nursing Forum, 38, 5, E382-E393.

Munro N. (2009) Hematologic complications of critical illness: anemia, neutropenia, thrombocytopenia, and more. American AACN Advanced Critical Care. 20, 2, 145-154.

Murphy SL, Xu J, \& Kochanek KD. (2013). Deaths: Final Data for 2010. National Vital Statistics Reports. 61, 4. Hyattsville, MD: National Center for Health Statistics
NANDA (2012). Nursing Diagnoses: Definitions and classification 2012-2014. USA: Mosby Elsevier

NANDA (2013). Nursing Interventions classification. Sixth edition. USA: Mosby Elsevier

Oberoi S., Suthar R., Bansal D., \& Marwaha R. K. (2013). Febrile Neutropenia: Outline of Management. Indian J Pediatr (February 2013) 80(2):138-143. Doi 10.1007/s12098-012-0901-y

O’Neill K.A., Bunch K.J., \& Murphy M.F., (2012). Intrauterine Growth and Childhood Leukemia and Lymphoma Risk. Expert Rev Hematol, 5,559-576

PPNI (2005). Standar kompetensi perawat Indonesia. 6 Juni 2015. http://www.inna-ppni.or.id

Rogers K. (2011). Blood Physiology and Circulation. New York: Britannica Educational Publishing

Roy C., \& Andrews A. H. (1999). The Roy Adaptation Model. Second edition. University Michigan: Appleton \& Lange

Schottenfeld D., Dimmer J. L. B., Buffler P. A., \& Omenn G. S. (2013). Current Perspective on the Global and United States Cancer Burden Attributable to Lifestyle and Environmental Risk Factors. Annual Review of Public Health, Vol. 34: 97-117. DOI: 10.1146/annurev-publhealth031912-114350 
Sposito A. M. P., Rodrigues F. M. S., Sparapani V. C., Pfeifer L. L., Lima R. A. G., \& Nascimento L. C. (2015). Coping strategies used by hospitalized children with cancer undergoing chemotherapy. Journal of Nursing Scholarship, 47:2, 143-151

Thibodeau G. A., \& Patton K. T., (2012) Structure and Function of the Body. Fourteenth edition. Mosby: St Louis.

Tomey, A.M. \& Alligood, M.R. (2006). Nursing theory utilization and application. Third Edition. St. Louis : Mosby Elsevier

Tomlinson, D., \& Kline, N, E. (2010). Pediatric onchology nursing advanced clinical handbook. $2^{\text {nd }}$ ed. Verlag Berlin Heidelberg: Springer.

Vedi A. et. al. (2015). Management of fever and neutropenia in children with cancer. Support Care Cancer 23:2079-2087. DOI $10.1007 / \mathrm{s} 00520-014-2572-\mathrm{x}$

Ward, E., DeSantia, C., Robbins, A., Kohler, B., \& Jemal. (2014). Childhood and adolescent cancer statistics, 2014. Cancer Journal for Clinicians, 64, 2, 83- 101. Doi.10.3322/caac.21219

Watson J., (2003). Caring science as sacred science. Philadelphia: F.A Davis Company

World Health Organization. (2012). Cancer. Diunduh tanggal 8 Oktober 2015. 